\section{Second wind for T cells}

\section{By Lev Osherovich, Senior Writer}

In the battle against HIV, HBV and HCV, all of which establish persistent infections that eventually wear down the antiviral cytotoxic $\mathrm{T}$ cell response, the odds for the immune system are poor. Three studies now show that blocking a bevy of $\mathrm{T}$ cell-inhibitory receptors can reverse this effect. The findings provide new validation for the approach taken by Medarex Inc., which has four products targeting such receptors in its cancer and HCV pipelines.

Two studies, published in Nature Immunology and the Proceedings of the National Academy of Sciences, used a murine lymphocytic choriomeningitis virus (LCMV) model of chronic viral infection to identify receptors that suppress cytotoxic T lymphocyte (CTL) response. ${ }^{1,2} \mathrm{~A}$ third study in Nature showed the efficacy of the strategy in a macaque model of HIV. ${ }^{3}$
Inhibitory receptors, which include cytotoxic T lymphocyte-associated protein 4 (CTLA4; CD152) and the related protein programmed cell death 1 (PDCD1; CD279; PD-1), ordinarily function to dampen excessive $\mathrm{T}$ cell activation that can lead to autoimmune disease.

However, chronic viral infection prompts $\mathrm{T}$ cells to upregulate CTLA4 and PD-1, thus undermining CTL activity and gradually driving T cells into a quiescent state termed exhaustion. Exhausted CTLs can no longer respond to virally infected host cells, leaving viruses free to replicate.

\section{Losing inhibition}

The Nature Immunology study identified surface receptors that work in parallel with PD-1 and CTLA4 to inhibit CTLs. These receptors could potentially be antagonized to increase the response to viral infection.

The research team had suspected that PD-1 and CTLA4 were not the only receptors that can turn down CTL responses. E. John Wherry, assistant professor of immunology at The Wistar Institute and lead author on the paper, told SciBX that previous efforts to treat viral infections by blocking either PD-1 or CTLA4 "improved the response, but not entirely."

To identify receptors with similar roles to PD-1 and CTLA4, the researchers used bioinformatics to create a list of candidate genes that are upregulated along with PD-1 in chronic viral infection.

"We used gene expression profiling to identify seven receptors and found that these receptors work together to fine tune" negative regula-

Table 1. Targeting inhibitory receptors to boost immunity. Blackburn et al. and Brooks et al. used a murine lymphocytic choriomeningitis virus (LCMV) model to identify receptors on cytotoxic T lymphocytes (CTLs) that could be targeted to increase the immune response to chronic viral infections such as HIV, HBV and HCV. This table summarizes the human homologs of potential targets described in the two studies. Unless otherwise noted, compounds mentioned below bind to the target.

\begin{tabular}{ll}
\hline Target name & Description \\
\hline CD160 & $\begin{array}{l}\text { Glycoprotein on CTL and peripheral blood } \\
\text { natural killer (NK) cells }\end{array}$ \\
\hline CD244; NK cell receptor 2B4 & $\begin{array}{l}\text { Glycoprotein expressed on the surface of CTLs } \\
\text { and NK cells }\end{array}$ \\
\hline CTL-associated protein 4 (CTLA4; & $\begin{array}{l}\text { Transmembrane receptor that sends an inhibitory } \\
\text { signal in activated T cells }\end{array}$
\end{tabular}

\section{Related compounds}

MAT302 antibody in preclinical development for solid tumors and wet age-related macular degeneration (AMD) from MAT Biopharma S.A.

Not applicable

Orencia abatacept, a CTLA4-Ig fusion protein that binds to B7-1 (CD80) and B7-2 (CD86), on the market for rheumatoid arthritis from Bristol-Myers Squibb Co. (NYSE:BMY); ipilimumab (MDX010) in Phase III for melanoma from Medarex Inc. (NASDAQ: MEDX)/Bristol-Myers; tremelimumab (CP-675206) in Phase II for various cancers from Pfizer Inc. (NYSE:PFE)

\begin{tabular}{ll}
\hline IL-10 receptor & $\begin{array}{l}\text { Receptor for IL-10; expressed on a variety of } \\
\text { lymphocytes }\end{array}$ \\
\hline $\begin{array}{l}\text { Leukocyte immunoglobulin-like } \\
\text { receptor, subfamily B (with TM } \\
\text { and ITIM domains), member 3 }\end{array}$ & $\begin{array}{l}\text { Transmembrane protein expressed on immune } \\
\text { cells that binds major histocompatibility } \\
\text { complex, class I molecules and sends inhibitory } \\
\text { signals }\end{array}$ \\
\hline $\begin{array}{l}\text { Lymphocyte-activation gene 3 } \\
\text { (LAG3; CD223) }\end{array}$ & $\begin{array}{l}\text { Transmembrane receptor expressed on T cells; } \\
\text { resembles CD4 }\end{array}$
\end{tabular}

Programmed cell death 1 (PDCD1; Transmembrane receptor that inhibits B cell and PD-1; CD279) T cell activity

IL-10 antibody from Schering-Plough Corp. (NYSE:SGP) used in the PNAS study by Brooks et al.

Not applicable

Target of a preclinical program at Medarex; ImmuTune IMP701 for cancer and ImmuTune IMP731 for autoimmune diseases and transplantation in preclinical development from Immutep S.A.

MDX-1106 antibody in Phase I for solid tumors and HCV infection from Medarex/Ono Pharmaceuticals Co. Ltd. (Tokyo:4528; Osaka:4528)

Ligand for PD-1 expressed on antigen-presenting MDX-1105 antibody in Phase I for solid tumors from Medarex cells and many tumor cells 


\section{TARGETS \& MECHANISMS}

tion of CTLs, said Wherry. "Almost all of the new targets we identified have not been studied in the context of chronic viral infections."

The team found six structurally unrelated surface proteins that played inhibitory roles in CTLs (see Table 1, "Targeting inhibitory receptors to boost immunity"). All had previously been implicated in negative regulation of hematopoietic cells in other immunological settings such as T cell development. In LCMV-infected mice, the receptors were upregulated in exhausted CTLs but not in naïve T cells.

In vitro cell-killing, apoptosis and cytokine-production assays suggested that no one receptor was entirely responsible for CTL inhibition. For example, treating exhausted CTLs with antibodies that blocked activation of two receptors, CD160 and CD244, increased overall CTL responses compared with untreated controls or with antibodies targeting several of the pathways individually.

The most promising candidate for an inhibitory role in vivo was lymphocyte-activation gene 3 (LAG3; CD223). LCMV-infected mice treated with antibodies against LAG3 had higher CTL activity and lower viral load than mock-treated controls.

Mice treated with a LAG3 antibody and a

\section{"Almost all of the new targets we identified have not been studied in the context of chronic viral infections." \\ -E. John Wherry, \\ The Wistar Institute}

Scripps, and David Brooks, now an assistant professor of microbiology, immunology and molecular genetics at the University of California, Los Angeles.

Although no patents were filed on the discoveries in the PNAS paper, Brooks noted that he and Oldstone previously sought patents on targeting IL-10 to treat viral infection. Neither Scripps nor ScheringPlough Corp. would disclose the licensing status of the antibodies used in the study, although the pharma did provide an antibody used to target IL-10 activity.

\section{Monkey bars virus}

Going forward, Brooks said he plans to test the combination therapy in a more advanced animal model, such as primates infected with simian immunodeficiency virus (SIV) or HCV.

A study published in Nature has already tested the effects of blocking PD-1 in SIV-infected macaques. That report suggests PD-1 blockade alone could decrease viral load and increase survival, and potentially could be combined with conventional antivirals to control HIV.

The study was led by Rama Rao Amara, assistant professor of microbiology and immunology at the Yerkes National Primate Research Center and the Emory Vaccine Center at Emory University.

Amara told SciBX that testing the role of PD-1 and other inhibitory receptors in SIV is likely to be more relevant to therapeutic development than mouse studies.

To combat SIV, he noted, "you need all three arms of the acquired immune system," including CTLs, antibody-producing B cells and helper $\mathrm{T}$ cells $\left(\mathrm{CD} 4^{+}\right.$cells). Helper $\mathrm{T}$ cells ordinarily enhance the activity of CTLs and B cells, but in SIV and HIV the helper cells themselves fall victim to the virus, thus keeping the entire immune system at bay.

PD- 1 is expressed in all three cell types, and Amara's team found that blocking PD-1 with antibodies improved the performance of the cell types in early and late stages of SIV.

Treating SIV-infected monkeys with PD-1 antibodies increased the number of SIV-reactive CTLs in the blood and gut compared with monkeys given control antibodies. The reawakening of CTLs led to increases in virus-fighting cytokines such as interferon- $\gamma($ IFN- $\gamma)$ and tumor necrosis factor- $\alpha$ (TNF- $\alpha$ ).

Moreover, the PD-1 antibody increased the production of SIV-specific antibodies compared with that seen in mock-treated controls. Amara said the inhibitory effect of PD-1 on B cells had not previously been appreciated.

"We show that the B cells express PD-1, and if you block PD-1 these cells proliferate and produce more antibodies," he said.

Rejuvenation of CTL and antibody activity against SIV eventually led to lower viral loads. SIV titers initially spiked upward in monkeys treated with PD-1 antibodies-presumably due to a burst of cell division by disinhibited but SIV-infected helper T cells. However, the spike tailed off as the CTL and B cell responses kicked in.

PD-1 inhibition had a pronounced effect on survival. All nine PD- 
Although a trio of papers shows the merits of blocking inhibitory receptors to treat viral infections, a paper in the Proceedings of the National Academy of Sciences highlights the potential pitfalls of targeting such receptors on all T cells. ${ }^{7}$

The study, from a team at University College London (UCL), implicates low levels of cytotoxic T lymphocyteassociated protein 4 (CTLA4; CD152) on regulatory $T$ cells as a factor in rheumatoid arthritis (RA). The findings raise the possibility that therapeutic lowering of CTLA4 signaling might also undermine the $T_{\text {reg }}$ response that keeps RA in check.

$T_{\text {regs }}$ ordinarily fine tune the behavior of other immune cells. In RA and other autoimmune diseases, the immune system fails to pick up on negative cues from $T_{\text {regs }}$ and goes into overdrive against self-antigens. Whereas CTLA4 activity inhibits most immune cells, the new study suggests that in $\mathrm{T}_{\text {regs }}$, CTLA4 has the opposite effect and actually promotes normal activity.

Previous efforts to target CTLA4 have aimed to decrease the receptor's activity on helper T cells. For example, Orencia abatacept, marketed by
Bristol-Myers Squibb Co. to treat RA, is a soluble fusion of CTLA4 and IgG that sponges up CTLA4's ligand and thus decreases CTLA4 activity.

The UCL team isolated $T_{\text {regs }}$ from RA patients and found lower levels of CTLA4 protein and CTLA4-related signaling activity compared with what was seen in healthy controls. As a result, $\mathrm{T}_{\text {regs }}$ from RA patients could not inhibit helper $T$ cells as effectively as could healthy $T_{\text {regs }}$.

In cultured $T_{\text {regs }}$ from RA patients, the team found that normal $T_{\text {reg }}$ activity could be restored by adding phorbol 12-myristate 13-acetate (PMA), a laboratory compound that short-circuits the inhibitory signaling pathways that keep CTLA4 levels low in RA.

Although it is still unknown whether $\mathrm{T}_{\text {reg }}$ activity is affected by indirect antagonists such as Orencia, UCL's Michael Ehrenstein told SciBX that the findings bode poorly for therapies that directly inhibit CTLA4. Ehrenstein is professor of experimental rheumatology and a senior author on the PNAS paper.

Ehrenstein noted that an earlier knockout study showed that mice lacking CTLA4 in $\mathrm{T}_{\text {regs }}$ are susceptible to autoimmune disease. ${ }^{8}$
"Simply blocking CTLA4 with an antibody would make things worse" for autoimmunity, he added.

"This research puts a note of caution to the large scale immunosuppressive therapy that is given to RA patients," agreed Claudia Mauri, senior lecturer in medicine at UCL and also a senior author on the paper. "Signaling through CTLA4 actually upregulates immunosuppressive mechanisms."

Although PMA is unsuitable as a therapeutic agent because of its broadly disruptive effects on cellular signaling, Mauri believes that other ways of inducing CTLA4 in $\mathrm{T}_{\text {regs }}$ could be a reasonable therapeutic strategy.

"We want to devise a lentivirus that upregulates or sustains the expres-


Therapy of this kind would most likely involve taking $T_{\text {regs }}$ out of the patient, transfecting them with extra CTLA4 and putting them back into circulation, she added.

Mauri and Ehrenstein's findings have not been patented, but the team has recently reported and sought patents on an in vitro method to stratify RA patients based on their $\mathrm{T}_{\text {reg }}$ responsiveness. ${ }^{9}$ $-\angle Z O$
1 antibody-treated monkeys were alive and healthy at 125 days posttreatment, whereas four of five monkeys treated with a control antibody died.

Wherry said Amara's study is "very important for the field since it both confirms and extends the PD-1 blockade approach to primates and SIV. This is a very significant advance, both in terms of the observation that the treatment was well tolerated by the mon-

keys and the improvement in immunity."

Amara told SciBX the data in the Nature paper bode well for the development of PD-1-directed adjuvants for conventional antivirals, which could be useful in treating HCV as well as HIV. He plans to develop a humanized version of the PD-1 antibody and to test the effects of blocking PD-L1.

"In theory, it's a viable approach to chronic viral infection. These data support further exploration" in larger monkey trials, said Mingjun Huang, executive director of antiviral drug discovery at Achillion Pharmaceuticals Inc.

Achillion is developing small molecule therapeutics to treat $\mathrm{HCV}$ and HIV. The company's lead compound is elvucitabine, a nucleoside reverse transcriptase inhibitor that has completed Phase II trials to treat HIV.

Huang said that although the effect of PD-1 blockade on survival was striking, viral titers eventually crept back up, perhaps because rapidly mutating virus can escape $\mathrm{T}$ cell-mediated and antibody-mediated immunity.

Amara agreed that mutational resistance by the virus may mean that antibodies raised by disinhibited B cells are only temporarily effective. He said the problem potentially could be avoided by raising anti-SIV antibodies at earlier stages of infection or by combining PD-1 therapy with standard small molecule antivirals, which could quash the virus before it gets a chance to mutate.

The work in the Nature study is the subject of a pending patent, but is not available for licensing, according to an Emory spokesperson.

"The SIV paper is very significant," said Nils Lonberg, SVP and scientific director at Medarex. "For me, the most dramatic thing is Emory University the last figure, where they show the reduction in viral load and increase in survival."

Medarex has at least four mAbs in clinical and preclinical development that target inhibitory receptors described in the three studies. The company's lead product, in development with Bristol-Myers Squibb Co., is ipilimumab (MDX-010), a CTLA4 antagonist in Phase III trials for melanoma and Phase I and II trials for other cancer indications. 


\section{TARGETS \& MECHANISMS}

According to Lonberg, cancer and chronic viral infection are "analogous" as far as CTL response is concerned-both tumor cells and virus-infected host cells thwart the immune system, and reinvigorating CTLs with inhibitory receptor blockade could thus be effective in both cases. As an example, he noted that Medarex's MDX-1106 PD-1 mAb, partnered with Ono Pharmaceuticals Co. Ltd., is in Phase I trials for both cancer and $\mathrm{HCV}$.

Medarex also is exploring other inhibitory receptor targets. In August, the company started an open-label Phase I trial of MDX-1105, a mAb that targets PD-L1, to treat cancer. The company also has a preclinical program targeting LAG3 to stimulate CTL activity.

\section{Combination therapy}

Targeting the new receptors in combination with PD-1 or PD-L1, or together with small molecule antivirals, could bypass the concerns about autoimmunity that have dogged CTLA4.

Wherry said that blocking some of the other receptors identified by his group and the Scripps team could bypass the autoimmune side effects of CTLA4 blockade that may make it an unsuitable target in chronic viral infections.

Low levels of CTLA4 have been implicated in the rampant autoimmunity that leads to rheumatoid arthritis (see Box 1, "Positive inhibition"). Side effects of CTLA4 antagonists in trials for cancer include autoimmune disorders such as irritable bowel disorder (IBD) and a pigment disorder called vitiligo.

In April, Pfizer Inc. discontinued a Phase III trial of its tremelimumab (CP-675206) CTLA4 antagonist in advanced melanoma, citing autoimmune side effects and nonsuperiority to standard chemotherapy. ${ }^{5}$ The pharma company is continuing Phase II trials in other cancer indications.

Lonberg said Medarex's MDX-010 has elicited inflammatory reactions in certain cancer patients, but that these adverse events could be controlled by careful monitoring and prompt treatment with steroids and Remicade infliximab. Remicade, a mAb that blocks TNF- $\alpha$, is marketed by Johnson \& Johnson to treat autoimmune disorders.

"We have a very carefully calibrated protocol for dealing with these events, so we're very comfortable with the safety of the drug," he said.

Brooks said his team did not see problems with autoimmunity in their mouse studies. Similarly, Amara said that in his monkey study, autoimmunity did not appear to be a problem.

However, Brooks did say such side effects are a concern for future clinical trials, especially ones involving multiple courses of therapy. "When you get out in a bigger population where treatments need to be repeated, there might be problems with autoimmunity," he said.

Brooks and Wherry both said further animal studies are needed to work out which combination of targets will strike the balance between antiviral response and autoimmunity. According to Wherry, the most suitable target may vary from person to person, depending on genetic makeup and the state of the immune system, and may differ for systemic infections like HIV compared with localized ones like HCV.

The normal role of the new receptors in slowing down CTL response against self-antigens needs to be explored further, said Dorian McGavern, an associate professor of immunology at Scripps who was not involved in the studies. "These braking systems are there for a reason," he said.

There is also debate about which viral indication would respond best to the disinhibition strategy. Wherry and Brooks think HCV would be ideal because of its restriction to the liver and its lack of a latent reservoir. In contrast, hidden pools of HIV in a variety of cell types have stymied efforts to completely eliminate the virus. ${ }^{6}$

However, Achillion's Huang believes that $\mathrm{HCV}$ would be prone to the same mutational escape mechanisms as HIV, and that HBV, which is more genetically stable, might be a better candidate for elimination by newly vigilant CTLs.

Regardless of indication, Lonberg acknow-ledged that the best use of inhibitory receptor blockers would likely be in combination with small molecule antivirals. "Antiviral drugs can tamp down replication, but it's the immune system that sweeps the floor for the last of the virus. So I think there's a real opportunity for immunomodulatory therapies to improve the efficacy of conventional antiviral therapies."

Osherovich, L. SciBX 1(45); doi:10.1038/scibx.2008.1092

Published online Dec. 18, 2008

\section{REFERENCES}

1. Blackburn, S. et al. Nat. Immunol.; published online Nov. 30, 2008; doi:10.1038/ni.1679

Contact: E. John Wherry, The Wistar Institute, Philadelphia, Pa. e-mail: jwherry@wistar.org

2. Brooks, D. et al. Proc. Natl. Acad. Sci. USA; published online Dec. 8, 2008; doi:10.1073/pnas.0811139106

Contact: Michael B.A. Oldstone, The Scripps Research Institute, San Diego, Calif.

e-mail: mbaobo@scripps.edu

Contact: David G. Brooks, University of California, Los Angeles, Calif. e-mail: dbrooks@em.ucla.edu

3. Velu, V. et al. Nature; published online Dec. 10, 2008; doi:10.1038/nature07662

Contact: Rama Rao Amara, Emory University, Atlanta, Ga. e-mail: ramara@emory.edu

4. Brooks, D.G. et al. Nat. Med. 12, 1301-1309 (2006)

5. Ribas, A. et al. Oncologist 12, 873-883 (2007)

6. Alexaki, A. et al. Curr. HIV Res. 6, 388-400 (2008)

7. Flores-Borja, F. et al. Proc. Natl. Acad. Sci. USA; published online Nov. 26, 2008; doi:10.1073/pnas.0806855105

Contact: Michael R. Ehrenstein, University College London,

London, U.K.

e-mail:m.ehrenstein@ucl.ac.uk

Contact: Claudia Mauri, same affiliation as above e-mail: c.mauri@ucl.ac.uk

8. Wing, K. et al. Science 322, 271-275 (2008)

9. Nadkarni, S. et al. J. Exp. Med. 204, 33-39 (2007)

\section{COMPANIES AND INSTITUTIONS MENTIONED}

Achillion Pharmaceuticals Inc. (NASDAQ:ACHN), New Haven, Conn. Bristol-Myers Squibb Co. (NYSE:BMY), Princeton, N.J. Emory University, Atlanta, Ga.

Johnson \& Johnson (NYSE:JNJ), New Brunswick, N.J.

Medarex Inc. (NASDAQ:MEDX), Princeton, N.J.

Ono Pharmaceuticals Co. Ltd. (Tokyo:4528; Osaka:4528), Osaka, Japan Pfizer Inc. (NYSE:PFE), New York, N.Y.

Schering-Plough Corp. (NYSE:SGP), Kenilworth, N.J.

The Scripps Research Institute, La Jolla, Calif.

University of California, Los Angeles, Calif.

University College London, London, U.K.

The Wistar Institute, Philadelphia, Pa.

Yerkes National Primate Research Center, Atlanta, Ga. 